\title{
EXPERIMENTAL INVESTIGATION OF COOLING AND LUBRICATION EFFECTS IN PLANE GRINDING OF AISI 304 STEEL
}

\author{
T. Leppert*
}

\begin{abstract}
Nowadays in grinding operations cooling and lubricating liquids are extensively used. Their application in many cases contributes to the lowering of the grinding temperature, energy consumption and improving surface quality. However, at the same time they pose a significant threat to the health of machine operators and contribute to the overall production costs. Therefore, there have been numerous attempts to eliminate or at least reduce their usage. In the presented investigation three methods of cooling and lubrication were used: with emulsion, minimum quantity lubrication $(M Q L)$ and grinding dry. The influence of these methods on the grinding force and surface roughness depended on the respective movements between the grinding wheel and workpiece and the selection of grinding speed. It was concluded that grinding dry of AISI 304 austenitic stainless steel leads to an increase of the grinding force whereas in $M Q L$ grinding the same force decreased. In the case of 304 steel the smallest values of surface roughness parameters appeared in MQL grinding compared to grinding dry and with emulsion.
\end{abstract}

Keywords: plane surface grinding, dry grinding, MQL grinding, grinding force, surface roughness

\section{Introduction}

The application of cooling and lubricating liquids in the grinding process has a significant impact on physical phenomena in the cutting zone, quality of the machined surface as well as geometrical accuracy of machined parts. For these reasons a large amount of cooling and lubricating liquid is delivered to the cutting zone during grinding process (Lawal et al., 2013 and Malkin et al., 2008). Prolonged exposure to coolants used in grinding operations may lead to multiple diseases of the machine operator. They also contribute to high costs of grinding processes (Silva et al., 2013). For these reasons, more and more scientific research has been performed on grinding dry or with MQL (minimum quantity lubrication), also referred to as near dry grinding by means of an air-oil mixture.

The impact of eliminating the cooling and lubricating liquid on the grinding force and temperature as well as geometrical/mechanical properties of machined parts was presented in many works (Klocke et al., 1997 and Brinksmeier et al., 1999), discussing potential possibilities and advantages of grinding dry provided that appropriate grinding conditions are applied, including grinding parameters and grinding wheel properties. Tawakoli et al., (2007) indicated that dry grinding is one of the most favorable processes from an economical and ecological point of view. However, reduction of harmful heat generation in the process is a rather difficult task, which often determines the process physical characteristics and surface integrity (Aurich et al., 2008). A good alternative to grinding dry, as previous investigations have shown, could be grinding with MQL, which can provide some cooling and lubrication in the tool-workpiece interface, and at the same time, reduce the amount of frictional heat or grinding force and improve the surface quality (Dhar et al., 2005 and Barczak et al., 2010). The literature review has shown that effects of cooling and lubricating methods on grinding force as well as the properties of the ground surface have not been fully examined - specifically in grinding of stainless steels. Therefore this article presents experimental investigations on the influence of dry, flood and MQL cooling and lubrication on the grinding force and surface roughness in plain grinding in a variable range of grinding speeds.

Assoc. Prof. Tadeusz Leppert, DSc, PhD.: Faculty of Mechanical Engineering, University of Science and Technology, Kaliskiego 7, 85-796 Bydgoszcz, PL, tleppert@utp.edu.p1 


\section{Materials and methods}

The research was performed on a universal plane grinding machine $3 \mathrm{G} 71$ with an aluminum oxide grinding wheel (95A80K6VT-43) sized $250 \times 25 \times 76 \mathrm{~mm}$. The machined samples were made of AISI 304 austenitic stainless steel. Before testing, both samples were pre-ground to standardize their thickness and surface roughness. After each test the grinding wheel was dressed with a single grain diamond dresser (dressing speed $v_{d}=25 \mathrm{~m} / \mathrm{s}$, dressing feed $f_{d}=0.1 \mathrm{~mm} / \mathrm{rev}$, dressing infeed $a_{d}=0.05 \mathrm{~mm}$ ). During testing the samples were ground with a constant work speed $v_{w}=0.25 \mathrm{~m} / \mathrm{s}$, cross infeed $a_{p}=1.5 \mathrm{~mm} /$ stroke and infeed rate $a_{e}=0.02 \mathrm{~mm}$ (Fig. 1). The grinding wheel speed equaled $v_{c}=25,30$ and $35 \mathrm{~m} / \mathrm{s}$. Each grinding test up-and down-grinding was repeated three times.

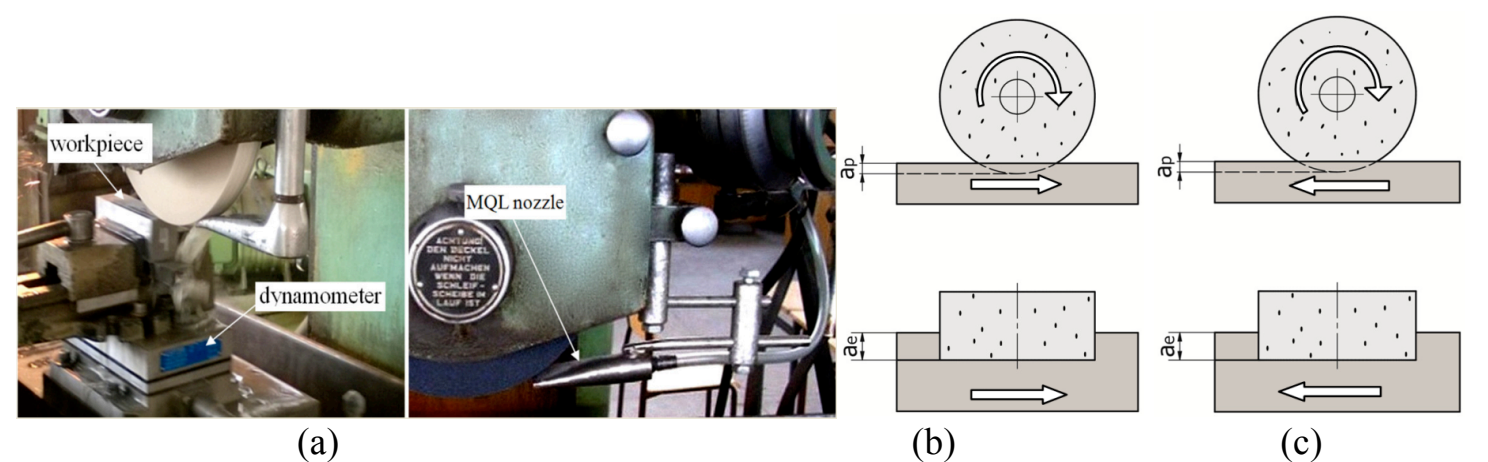

Fig. 1: Work station (a) and grinding process: (b) up-grinding, (c) down-grinding

In the experiments the following methods of cooling and lubricating of the grinding zone were used:

(a) dry - without any cooling liquid,

(b) with minimal quantity lubrication (aerosol pressure $35 \mathrm{MPa}$, oil consumption $50 \mathrm{ml} / \mathrm{h}$ ),

(c) with 6 vol\% emulsion (flow rate $61 / \mathrm{min}$ ).

The oil aerosol was generated by an Acu-Lube Minibooster MBII with a LB8000 vegetable oil. The oil aerosol was delivered by a specially designed nozzle, positioned toward the grinding wheel and located at a distance of $40 \mathrm{~mm}$ to the grinding zone. The emulsion was made from emulsifying oil ARTEsol Super EP, containing up to $46 \%$ of mineral oil and $15 \%$ of additives.

The grinding force was measured during grinding dry, with MQL and emulsion using a Kistler 9247B piezoelectric dynamometer. In the analysis of the impact of cooling and lubrication method on the grinding force the tangential component $F_{t}$ was used because of the smallest scatter of its values. The measurement of the tangential component was done for down-grinding and up-grinding.

The measurement of the surface roughness profile parameters was performed on a Hommel profile tester (Tester T2000) with traverse length $4.8 \mathrm{~mm}$, sampling length $0.8 \mathrm{~mm}$, evaluation length $4.0 \mathrm{~mm}$. The following surface roughness parameters were measured: arithmetic mean deviation of the profile height $R a$ and maximum height of the profile $R z$. The measurements of these parameters were repeated at five different points and mean values and standard deviations of the measurement results were calculated.

\section{Results and discussion}

\subsection{Grinding force}

In grinding AISI 304 austenitic stainless steel the value of the tangential grinding force $F_{t}$ depended on the cooling and lubrication method, grinding speed and the grinding wheel-workpiece movement kinematic relationships (Fig. 2). Eliminating the cooling liquid from the process led to a significant increase in the grinding force. Compared to grinding with emulsion its value was higher, ranging from 0 to $12 \%$ as the cutting speed increased both in up- and down-grinding. For the former, however, the increase was greater, resulting from higher plastic deformations generated during chip formation. This relation between the grinding force and speed was caused by a change in mechanical properties of 304 steel, especially its tendency to become work-hardened due to the thermal and force related interactions during grinding. Another reason was the tendency to growing adhesion between the grinding grains and ground steel in higher temperatures during dry grinding, which contributed to an increased friction (Aurich et al., 2008). The application of MQL caused a substantial decrease in the force value in the 
whole range of the used cutting speeds, both in up- and down-grinding, indicating a positive impact of the oil aerosol on the grinding process in the chip formation zone. The values of the tangential force in downgrinding were lower than those for up-grinding, which was the effect of different lubrication and chip formation conditions of the abrasive grains. Depending on the grinding speed the differences between these values were in the range of 3-7\%. Increasing the grinding speed from $20-35 \mathrm{~m} / \mathrm{s}$ in grinding dry and with emulsion caused a significant increase in the grinding force $F_{t}$, as a result of the material hardening due to the increased cooling action and pressure of the emulsion layer created on the revolving grinding wheel by increasing the circumferential speed and increased wear of abrasive grains. An opposite influence was observed in grinding with MQL. The grinding force decreased by about $5 \%$ both in up- and down-grinding, indicating reduced friction in the grinding wheel-workpiece interface, lower material plastic deformations and work-hardening at lower grinding force. The best grinding conditions from the point of view of the grinding force were observed in MQL grinding, because its values were lowest in the whole range of the used speeds and ranged from 77 to $84 \mathrm{~N}$.

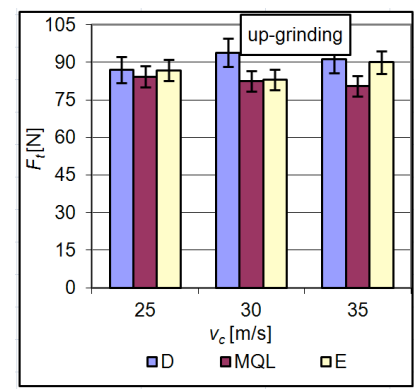

(a)

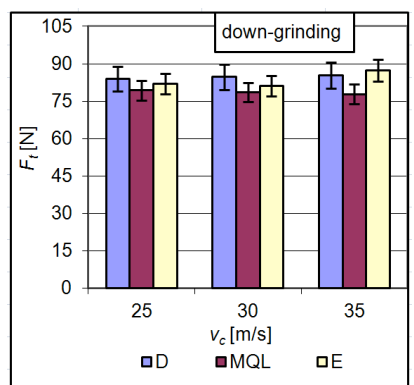

(b)

Fig. 2: Impact of cooling and lubrication method and grinding speed on grinding force $F_{t}$ : (a) up-grinding, (b) down-grinding

\subsection{Surface roughness}

Results indicate that the method of cooling and lubrication in the cutting zone had a huge impact on surface roughness in grinding AISI 304 stainless steel (Fig. 3). Out of all the used methods of cooling and lubrication, the lowest roughness values were recorded after grinding with MQL. The $R a$ values ranged from 0.40 to $0.43 \mu \mathrm{m}$, depending on the cutting speed. Their standard deviation values were also very small. The low surface roughness after MQL grinding can be assigned to effective lubrication of the abrasive grains directly at the workpiece-tool interface and lower cutting force (Fig. 2).

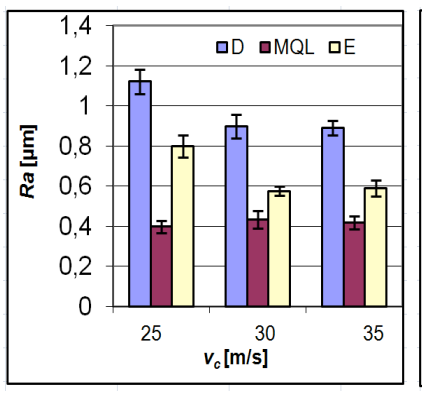

(a)

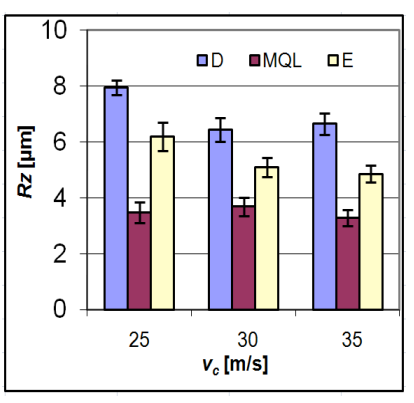

(b)

Fig. 3: Impact of cooling and lubrication method and grinding speed on surface roughness: (a) $R a$ and (b) $R z$

Efficient lubrication resulted in a smaller adhesiveness of chips to the grinding wheel, which caused the chips to slide more easily over the tool surface and led to reduced forces. Higher surface roughness occurred after grinding with emulsion, especially at a speed of $25 \mathrm{~m} / \mathrm{s}$ when the $R a$ value was around $0.8 \mu \mathrm{m}$ as a result of increased surface plastic deformations caused by the increased grinding force and possible surface work-hardening. Eliminating cooling liquid in grinding dry resulted in greatly increased surface roughness. The $R a$ value at this speed equaled $1.12 \mu \mathrm{m}$ and was highest in the whole range of the used grinding speeds. The possible reasons were a high grinding force, (comparing to other cooling and lubrication methods) and surface heat flaws caused by the grinding wheel wear. Additionally the highest 
ground surface temperature was observed. Similar relations were noticed for the $R z$ parameter. The increase of the grinding speed in the whole range of the used values did not have any significant influence on surface roughness in grinding with MQL, compared to grinding dry and with emulsion. The efficient penetration of the lubrication aerosol stream at the grinding wheel-workpiece interface secured the comparable grinding conditions. However, in grinding dry and with emulsion increasing the speed from 25 to $30 \mathrm{~m} / \mathrm{s}$ led to significantly lower surface roughness. A further increase in the speed up to $35 \mathrm{~m} / \mathrm{s}$ did not cause any substantial change in the $R a$ and $R z$ values, which means that this grinding speed can be the most recommended for grinding AISI 304 steel dry, with MQL and emulsion.

\section{Conclusions}

The presented investigation showed a significant impact of the cooling and lubrication method on the grinding force as well as surface roughness in grinding AISI 304 austenitic stainless steel.

Eliminating widely used machining emulsions - grinding dry caused a great increase in the grinding force compared to grinding with emulsion and MQL. The lowest values of $F_{t}$ force in most of the used grinding speeds and cooling methods were observed for MQL, both in up- and down-grinding. In the used range of grinding conditions, the grinding force became lower as the grinding speed increased. The value of $F_{t}$ force during down-grinding was lower than during up-grinding but the differences were not significant.

Using MQL resulted in lower surface roughness of the ground surfaces compared to grinding dry and with emulsion. Grinding dry resulted in much worse surface roughness compared to other cooling and lubrication methods. In MQL grinding the impact of the grinding speed on surface roughness was insignificant. The impact of the grinding speed in the range used in the investigation depended on the cooling and lubrication method.

\section{References}

Aurich, J.C., Herzenstiel, P., Sudermann, H., Magg, T. (2008) High-performance dry grinding using a grinding wheel with a defined grain pattern. CIRP Ann-Manuf Techn, 57, pp. 357-362.

Barczak, L.M., Batako, A.D.L., Morgan, M.N. (2010) A Study of plane surface grinding under minimum quantity lubrication (MQL) conditions. International Journal of Machine Tools \& Manufacture, 50, pp. 977-985.

Brinksmeier, E., Walters, A., Janssen, R. (1999) Aspects of cooling lubrication reduction in machining advanced materials. Proceedings of the Institution of Mechanical Engineers Part B Journal of Engineering Manufacture, 213 (8), pp. 769-778.

Dhar, N.R., Hossain, M., Kamruzzaman, M. (2005) MQL applications in grinding of 16MnCr5 steel: a comparison with wet and dry grinding. Proceedings of the International Conference on Mechanical Engineering, (ICME2005) Dhaka, Bangladesh, pp. 28- 30.

Klocke, F., Eisenblaetter, G. (1997) Dry cutting. Annals of the CIRP, 46(2), pp. 519-526.

Lawal, S.A., Choudhury, I.A., Nukman, Y. (2013) A critical assessment of lubrication techniques in machining processes: a case for minimum quantity lubrication using vegetable oil-based lubricant. Journal of Cleaner Production, 41, pp. 210-221.

Malkin, D., Guo, C. 2008. Grinding Technology: Theory and Applications of Machining with Abrasives. 2nd ed. New York: Industrial Press Inc.

Silva, L.R., Correa, E.C.S., Brandao, J.R., de Avila, R.F. (2013) Environmentally friendly manufacturing: Behavior analysis of minimum quantity of lubricant - MQL in grinding process. Journal of Cleaner Production. doi: 10.1016/j.jclepro.2013.01.033.

Tawakoli, T., Westkaemper, E., Rabiey, M. (2007) Dry grinding by special conditioning. International Journal of Advanced Manufacturing Technology, 33, pp. 419-424. 